University of Wollongong

Research Online

Faculty of Commerce - Papers (Archive)

Faculty of Business and Law

March 2004

\title{
Quantifying the Effect of GST on Inflation in Australia's Capital Cities: An Intervention Analysis
}

\author{
Abbas Valadkhani \\ University of Wollongong, abbas@uow.edu.au
}

A. P. Layton

Queensland University of Technology

Follow this and additional works at: https://ro.uow.edu.au/commpapers

Part of the Business Commons, and the Social and Behavioral Sciences Commons

\section{Recommended Citation}

Valadkhani, Abbas and Layton, A. P.: Quantifying the Effect of GST on Inflation in Australia's Capital Cities: An Intervention Analysis 2004.

https://ro.uow.edu.au/commpapers/400

Research Online is the open access institutional repository for the University of Wollongong. For further information contact the UOW Library: research-pubs@uow.edu.au 


\title{
Quantifying the Effect of GST on Inflation in Australia's Capital Cities: An Intervention Analysis
}

\author{
Abstract \\ This paper examines the magnitude and duration of the GST effect on inflation in Australia's eight capital \\ cities using the Box and Tiao intervention analysis and quarterly data spanning from 1948:4 to 2003:1. We \\ found that GST had a significant but transitory impact on inflation only in the September quarter of 2000 \\ when this new tax system was implemented. In this quarter inflation showed an additional increase of 2.6 \\ per cent in Sydney (minimum effect) and 2.8 per cent in Australia as a whole, the same figure for Hobart \\ was 3.3 per cent (maximum effect). Based on the Wald test results, we have also found some evidence \\ that there is no significant (or substantial) difference in the average price changes among capital cities. \\ We could not reject the null hypothesis that GST increased the CPI by 2.8 per cent across the board in \\ various cities. These results are also consistent with previous studies/surveys. Keywords: Intervention \\ Analysis; State and Local Taxation; Australia.

\section{Keywords} \\ Inflation, GST, Australia, Intervention analysis

\section{Disciplines} \\ Business | Social and Behavioral Sciences

\section{Publication Details} \\ This article was originally published as Valadkhani, A., Layton, A.P., Quantifying the Effect of GST on \\ Inflation in Australia's Capital Cities: An Intervention Analysis, Australian Economic Review, 37(2), 2004, \\ 125-38. Original article available at www.blackwell-synergy.com
}




\title{
Quantifying the Effect of GST on Inflation in Australia's Capital Cities: An Intervention Analysis
}

\author{
Abbas Valadkhani and Allan P. Layton \\ School of Economics and Finance, Queensland University of Technology,
}

\begin{abstract}
This paper examines the magnitude and duration of the GST effect on inflation in Australia's eight capital cities using the Box and Tiao intervention analysis and quarterly data spanning from 1948:4 to 2003:1. We found that GST had a significant but transitory impact on inflation only in the September quarter of 2000 when this new tax system was implemented. In this quarter inflation showed an additional increase of 2.6 per cent in Sydney (minimum effect) and 2.8 per cent in Australia as a whole, the same figure for Hobart was 3.3 per cent (maximum effect). Based on the Wald test results, we have also found some evidence that there is no significant (or substantial) difference in the average price changes among capital cities. We could not reject the null hypothesis that GST increased the CPI by 2.8 per cent across the board in various cities. These results are also consistent with previous studies/surveys. Keywords: Intervention Analysis; State and Local Taxation; Australia.

JEL codes: C22; E31; H71; C22.
\end{abstract}




\section{Introduction}

On 1 July 2000 (the beginning of the third quarter or 2000:3) A New Tax System (ANTS) was implemented, whereby "most goods and services became subject to GST equivalent to one-eleventh of the selling price, some goods and services were GSTfree and some were input taxed" (Australian Competition and Consumer Commission, ACCC, 2003, p.2). The Commonwealth Treasury (2000) of Australia believes that this major tax reform is the largest structural change to the Australian economy since World War II.

The ANTS has also had very important implications for social security systems, business tax, indirect tax, income tax, and Commonwealth-State financial relations. See Dawkins and Johnson (1998) for a general discussion on the interaction between the tax and social security systems in Australia. Prior to the introduction of GST, Johnson, Freebairn and Scutella (1999) thoroughly evaluated the revenue, efficiency and equity effects of the indirect tax changes associated with the government's tax package. They argued that in the long run both reductions in personal income tax and increases in social security rates could sufficiently attenuate the average price rises among broad groups of households. After almost three years, it is now important to examine the extent to which the GST has impacted on inflation in various parts of Australia.

As can be seen from the brief review of the relevant literature presented below, various studies/surveys have already examined the effect of the GST on inflation. However, our contribution to such an important issue is twofold. First, this paper uses a totally different approach to examine systematically the size and duration of the GST effects on inflation not only in Australia as a whole but also in its eight capital cities, namely, Adelaide, Brisbane, Canberra, Darwin, Hobart, Melbourne, 
Perth, and Sydney. Although previous studies/surveys (undertaken by the ACCC, the Commonwealth Treasury and various State Treasuries) have already examined this issue, they use different approaches and/or different survey data. Enough aggregated quarterly time series data are now available since the introduction of GST to enable a meaningful econometric analysis to be used to examine this issue for each major city in the Commonwealth.

This study can therefore provide a consistency check on the impact and duration of the GST effect. The relevant review of literature indicates that the various studies/surveys have provided slightly different estimates for the GST effect. Under various assumptions and approaches, these estimates also vary through time (See various estimates of the ACCC in different surveys discussed below). It seems that with the passage of time these estimates have become more accurate and differences are now being narrowed, resulting in a consensus among analysts in relation to the effect of GST on inflation.

The second contribution we believe the paper makes is that almost all previous studies have indicated that the effect of GST on inflation was one-off and of transitory nature but they have not been very specific as to the duration of the GST effect. For example, the ACCC (2001, p.2) has estimated the effect of GST on inflation during third and fourth quarters of the year 2000 to be around 4 per cent, with 3.7 per cent occurring in the September quarter 2000. The Commonwealth Treasury (2000, p.11) expected that the ANTS would "add around 23/4 percentage points to the CPI through the year to the June quarter 2001".

The present study uses quarterly data - with inflation defined as quarter-toquarter log changes - and clearly finds that the GST effect on inflation in all cities was statistically significant only in the September quarter of 2000, suggesting no 
significant effect in any of the four prior or subsequent quarters. As seen later in this paper although the point estimates for the eight capitals varied from 2.6\% in Sydney to $3.3 \%$ in Hobart, these differences were not found to be statistically significant from the national point estimate of $2.8 \%$. To the best of our knowledge the present study is the only independent (i.e. non-government) study which quantifies the size and duration of the GST effect on inflation at an aggregate level and for various capital cities. We present below a brief review of the relevant literature prior to discussing our theoretical framework

Warren et al. (1999) within the National Centre for Social and Economic Modelling (NATSEM) modelled the distributional impact of the implementation of the Government's ANTS tax package under ten possible scenarios. According to this comprehensive study, with different sets of assumptions and depending which scenario is considered, the effect of this tax reform on inflation was predicted to be between 0.8 per cent and 3.6 per cent. Warren et al. $(1999,1)$ also argue that according to their first scenario, which is exactly the methodology adopted by the Treasury in measuring the distributional impact of this reform, inflation would increase by 2.0 per cent which is quite near the Treasury's estimate.

As mentioned above, according to the Commonwealth Treasury (2000, p.11) and Queensland Treasury (2001, p.1), the GST increased the CPI by 2.75 per cent through the year to the June quarter 2001. It is widely believed that apart from this one-off price-perturbation, inflationary pressures would remain low (New South Wales Treasury, 2001, and Queensland Treasury, 2001). Examining this same issue, New South Wales Treasury (2001, p. 14) states that "while the ABS has not been able to publish a conclusive estimate of the impact from the GST on the September quarter 
CPI, the Commonwealth Treasury and private sector estimates are mostly in the range of $2^{1 / 2}-3$ percentage points".

During the GST transition period the ACCC $(2001,2003)$ has also conducted eight general surveys (December 1999-January 2000; March, May, August, and October 2000; and February and May 2001), in which prices for various goods and services were collected from about 10,000 retail outlets in 115 geographical locations (i.e. major capital cities, regional cities, towns etc in all states and territories). The Commission's retail price surveys do not represent an economy-wide measure of the effects of GST and therefore one cannot compare them directly to the CPI compiled by the ABS. However, they provide a rough estimate of the impact of GST on inflation. According to the ACCC (2001, p.2), the effect of ANTS on inflation during third and fourth quarters of the year 2000 is expected to be around 4 per cent, with 3.7 per cent occurring in the September quarter 2000. The ACCC (2001, p.14) has also estimated an upper estimate of the short-term effects of the ANTS on prices to be around 3.0 per cent.

More recently the ACCC (2003) in its final report on GST made 320,000 price comparisons between the survey in May 2000 (the pre-GST base period) and the May 2001 survey (post-GST period). The ACCC (2003, p.11) found that "the weighted average price change over the three months between the May and August 2000 surveys was +2.6 per cent. Weighted on the same basis, the Commission's estimate of the effects of the ANTS by the end of 2000 was an increase of 3 per cent. The weighted average price change over 12 months between the May 2000 and May 2001 surveys, by which time non-tax factors were generally determining prices outcomes, was +5.7 per cent." The ACCC also argues that price changes caused by the implementation of the ANTS were "fairly consistent across geographical locations 
even though price levels may have been quite different. The results also showed no substantial differences in the average price changes between the states and territories, although again prices may have been at different levels" (2003, p.11). It should be noted that the results obtained from the present study also confirm this issue. Table 1 summarises these estimates.

\section{[Table 1 about here]}

The GST was an important component of the ANTS package. However, it should be noted that the ANTS package was a more comprehensive reform which encompassed the sequential adjustment and removal of the wholesales tax and changes to excise taxes as well as the introduction of the GST. It is important to recognise that it is very difficult to separate the GST effect from the effect associated with other components of the ANTS package through time. One should note that we have used time series data on the CPI which reflects (simultaneously) all price changes associated with the ANTS package (including the GST effect) at an aggregate level. Therefore, in this paper we have used the term "GST" as a generic term for the ANTS package. In this paper both "GST" and "ANTS" are employed interchangeably.

The structure of this paper is as follows: Section 2 presents a brief review of the theoretical framework of the Box and Tiao intervention analysis. Section 3 provides some relevant time series data on the phenomena to be explained. This section also examines the time series properties of the data. The empirical econometric results and the policy implications of the paper are discussed in Section 4. Finally some concluding remarks will follow in Section 5. 


\section{Theoretical Framework}

Since the CPI data are collected over time in regularly spaced intervals (i.e. quarterly) and the timing of intervention (the introduction of GST) is also known, we use the Box and Tiao (1975) intervention analysis to examine the impact of this policy change on inflation through time. This approach uses the Box-Jenkins methodology in which an Autoregressive Integrated Moving Average (ARIMA) type model is augmented by dummy variables to evaluate the effects of unusual events. Since Box and Tiao introduced this useful technique in 1975, many analysts have used it in a wide variety of applications (inter alia, see Enders, Todd, and Parise, 1992; Enders, Sandler, and Cauley, 1990; Hogan, 1984; and Thompson and Noordewier, 1992). For example, Bhattacharyya and Layton (1979) and Harvey and Durbin (1986) have applied the intervention analysis framework (augmented with a causal variable) to analyse the effects of seatbelt laws on road fatality rates in Australia and Britain, respectively. Layton (1983) and Layton and Weigh (1983) also used the approach to investigate the efficacy of introducing random breath testing and increased penalties on the incidence of drink driving in Australia.

Lloyd, Morrissey and Reed (1998) employed intervention analysis to estimate the effect of anti-dumping and anti-cartel actions in the context of the European Commission. Sharma and Khare (1999) have analysed the effectiveness of CO pollution control legislation in India using the univariate ARIMA intervention analysis. More recently, Bausell et al. (2001) have also used this technique to examine the long-run price effects on crude oils of removing the U.S. export ban on Alaskan North Slope crude oil.

In order to facilitate the analysis and the interpretation of the empirical results, we have used the logarithmic transformation, which allows us to (a) consider 
percentage changes rather than absolute shifts and (b) stabilizes the variance of the series. In this paper the following general ARIMA process of order $(k, d, q)$ is estimated:

$\Phi_{k}(L) \Delta^{d} \Delta_{r}^{s} p_{t}=\mu+\Theta_{q}(L) \varepsilon_{t}+\beta D_{t}$

where $\Phi_{k}(L)$ represents a $k$-order polynomial lag operator; $\Delta^{d}$ and $\Delta_{r}^{s}$ denote the ordinary difference and seasonal difference operators, respectively; $d$ and $s$ are the number of times these differences are applied; $r$ is the seasonal lag term; $p=\ln (P) ; P$ is the consumer price index $(\mathrm{CPI}) ; \mu$ is a constant, $\Theta_{q}(L)$ denote a $q$-order polynomial lag operator; $\varepsilon$ is a white noise process; $k$ is the number of autoregressive terms; $q$ is the number of moving-average terms; $D_{t}$ is the intervention (or dummy) variable.

Whilst not behaviourally explaining the inflation process, the ARIMA model should nonetheless capture any underlying systematic time series patterns in the data (of which seasonality would be the most obvious). It is important that such systematic time series patterns in the fluctuations in the data be accounted for so as to accurately gauge the impact of the intervention itself. The magnitude of $\beta$ will represent the effect of the introduction of GST on the rate of inflation beyond what could have been expected on the basis of the discernible systematic pattern of fluctuation in the data.

It is also important to recognise that an intervention such as the introduction of the GST may well have only an immediate and temporary impact on the rate of inflation in the quarter in which it is introduced. Such an immediate and temporary impact could be well captured by a variable such as $D_{t}$, a dummy variable taking the value of zero everywhere except in the quarter in which the GST was introduced, viz. the September quarter, 2000.

On the other hand, there is the possibility that the effect of the intervention may persist beyond the period of introduction. In the case of the GST this might occur 
if the initial impact on prices gave rise to some residual momentum of further price rises. This may arise from either subsequent nominal wage growth increasing cost pressures or simply a further round of price rises deriving from a belief on the part of price setters that they may be able to extract additional price rises from consumers as a result of the initial price rise impetus coming about from the introduction of the GST. In order to test this possibility we allow the GST to impact on inflation for up to five quarters by initially including a further four pulse dummies (each with a non-zero value of 1 in only the relevant subsequent quarter: i.e. December, March, June, September). In other words, it is hypothesized that the GST effect (if any) on inflation is exhausted by the September quarter of 2001.

Thus, in sum, in order to separate the immediate impact effect from any subsequent effects of the GST on inflation, the following pulse dummy variables are incorporated into the model: $D_{1}$ takes on the value of 1 in the third quarter of 2000 (when the GST was introduced) and zero otherwise; $D_{2}$ takes on the value of 1 in the fourth quarter of 2000 (2000:4) and zero otherwise; $D_{3}$ takes on the value of 1 in the first quarter of $2001(2001: 1)$ and zero otherwise; $D_{4}$ takes on the value of 1 in the second quarter of 2001 (2001:2) and zero otherwise; and $D_{5}$ takes on the value of 1 in the third quarter of 2001 (2001:3) and zero otherwise. The duration of the GST effect on inflation is then simply a matter of empirical investigation, which can be examined by testing for the statistical significance of these dummy variables in the intervention model.

In addition to identifying an ARIMA process, one should test seasonality of quarterly data on inflation as the headline inflation data are quite often subject to seasonal variations. Box, Jenkins, and Reinsel (1994) suggest that a seasonal autoregressive term should also be incorporated into monthly or quarterly models to 
account for systematic seasonal movements. In order to address this possibility, equation (1) has also been augmented by a seasonal autoregressive term.

As part of the estimation process one needs first to choose accurate values for $k, d, r$ and $q$ in the specification the ARIMA model. The identification of an ARIMA model is not an "exact science" but as a rule of thumb, spikes in the Autocorrelation (AC) function and the Partial Autocorrelation (PAC) are used to determine $q$ and $k$, respectively. The estimated model is then subjected to a range of diagnostic checks on the residuals to ensure that all systematic variation in the time series has been properly accounted for by the model.

It is also important that the series being modeled is stationary. In this analysis, as expected, the log CPI levels series proved to be non-stationary. However, their first differences - effectively quarterly rates of price change or quarterly inflation rates satisfied the usual tests of stationarity (see Table 3). Thus for each city we use quarterly inflation rates as the dependent variable denoted by $\mathrm{y}_{\mathrm{t}}$. The generic equation used to model the data on each capital city (and for Australia as a whole) is as follows:

$$
\left(1-\rho_{1} L-\rho_{2} L^{2}-\ldots \rho_{k} L^{k}\right)\left(1-\phi L^{r}\right) y_{t}=\mu_{0}+\left(1-\theta_{1} L-\theta_{2} L^{2}-\ldots \theta_{q} L^{q}\right)+\sum_{i=1}^{5} \beta_{i} D_{i t}+w_{t}
$$

\section{The Data}

The basic data employed in this study were quarterly time series data for the consumer price index of the eight capital cities in Australia. These cities are as follows: Adelaide, Brisbane, Canberra, Darwin, Hobart, Melbourne, Perth and Sydney. The data for all these cities (including Australia as a whole) are available from the third quarter of 1948 (i.e 1948:3) to the first quarter of 2003 (i.e. 2003:1), with the only exception being Darwin for which the data are available only from 
1980:4. Table 2 presents the summary statistics of the data employed on quarterly rate of inflation in these eight cities as well as that of Australia as a whole. During the 1948:4-2003:1 period both the mean and standard deviation of inflation per quarter across seven of these eight cities have varied from 0.13 to 0.14 , suggesting that the relative volatility of inflation is the same among these capital cities.

\section{[Table 2 about here]}

Using all available data, Figure 1 plots the inflation rate, defined as $\Delta \ln \left(P_{t}\right)$, in these eight cities plus the weighed average rate of inflation for Australia as a whole. ${ }^{1}$ A cursory inspection of these graphs clearly shows an abnormal spike in the third quarter of 2000, which coincides with the introduction of the ANTS. The dotted lines in Figure (1) also suggest that the GST effect on inflation is considerable only in 2000:3. However, one needs to use a more formal technique to properly evaluate this proposition.

\section{[Figure 1 about here]}

The Augmented Dickey-Fuller (ADF) test and the Kwiatkowski-PhillipsSchmidt-Shin (KPSS, 1992) test, have been used to examine the stationarity, or otherwise, of the time series data. Table 3 presents the results of applying the ADF and KPSS tests to the data. On the basis of these results, $\mathrm{p}$ or the $\log$ of consumer price index is $\mathrm{I}(1)$ and the rate of inflation is $\mathrm{I}(0)$ in seven out of eight capital cities, namely Adelaide, Brisbane, Canberra, Hobart, Melbourne, Perth and Sydney and also Australia as a whole. However, in the case of Darwin the results of the ADF test and the KPSS test are contradictory. This could be due to the fact that the number of quarterly observations for Darwin is considerably less than those of other seven cities.

\footnotetext{
${ }^{1}$ Australia's inflation rate is a weighted average of the inflation rates in these eight capitals, the weights being each region's population.
} 
Given that in all the other cities (including Australia as a whole) $p$ is I(1), the authors have also assumed that the CPI in Darwin is also I(1).

[Table 3 about here]

\section{Empirical Results and Policy Implications}

The aim of this section is to shed light on the following three questions: (a) as a result of the introduction of the ANTS, how much did inflation rise in each city and for Australia as a whole; (b) for how long did the ANTS affect inflation? In other words, was inflation only a one-off phenomenon or did its effects persist for a number of quarters?; and (c) was there any significant difference among these eight capital cities in terms of the magnitude of price changes? As it was mentioned in Section (1), many previous studies and/or surveys have already tried to provide convincing answers to these questions, but this paper uses a totally different technique to systematically undertake a consistency check on the results obtained previously and also shed some further light on the size and duration of the GST effect on inflation.

Equation (2) was estimated for eight capital cities and Australia and the results are presented in Table 4. As can be seen, the estimated ARIMA intervention models pass all diagnostic tests. ${ }^{2}$ The estimated Ljung and Box (1978) $Q$-statistics (up to 24 lags) and the $L M$ (Lagrange Multiplier test for serial autocorrelation up to 4 lags) in Table 4 and the correlograms of the resulting residuals for the estimated equations in Figure 2 clearly indicate that the ARIMA intervention models are statistically quite acceptable. All estimated coefficients for $\phi, \rho$ and $\theta$ are statistically significant and the inverted AR and MA roots have modulus less than one, suggesting that the estimated

\footnotetext{
${ }^{2}$ EViews 4.1 (2002) was used in the estimation process.
} 
ARIMA models are stationary (the inverted AR and MA roots have not been reported here but they are available from the authors upon request).

[Table 4 about here]

\section{[Figure 2 about here]}

Among the estimated coefficients for $\beta_{i}$, only $\beta_{l}$ is positive and statistically significant in all eight capital cities. In other words, according to the empirical results in Table 4, the introduction of GST would appear to have increased quarterly inflation only in the September quarter of 2000. Therefore one may conclude that the duration of the GST effect was confined to 2000:3. As noted above, Figure 1 also informally confirms this finding.

Given that none of the estimated coefficients for $\beta_{2}$ to $\beta_{5}$ were statistically significant, we excluded these pulse dummy variables (i.e., $D_{2}$ to $D_{5}$ ) from the model and re-estimated these equations. Table 5 presents the estimated coefficients for $\beta_{l}$ for all of eight capital cities (plus Australia as a whole) when the insignificant pulse dummy variables are excluded from the estimated model. In order to make comparison easier, we have also reported the earlier estimates of $\beta_{l}$ (already presented in Table 4) in the second column of Table 5. A cursory look at the estimated coefficients for $\beta_{1}$ across all the eight capital cities shows that these estimates have not changed considerably.

\section{[Table 5 about here]}

Based on the first column in Table 5 one can argue that the introduction of GST increased the rate of inflation in the September quarter of 2000 by 2.9 per cent in Adelaide, 3.2 per cent in Brisbane, 2.9 per cent in Canberra, 2.7 per cent in Darwin, 3.3 per cent in Hobart (maximum effect), 3.1 per cent in Melbourne, 3.1 per cent in Perth, 2.6 per cent in Sydney (minimum effect) and 2.8 per cent in Australia. The 
effect of GST on inflation (measured by percentage changes in the headline CPI) in Australian capital cities is also shown in Figure 3. These results are very consistent with previous studies and/or surveys outlined in Section 1.

We have also examined the sensitivity of the estimated coefficients of the pulse dummy variables (particularly the $\beta_{l}$ coefficient) to different sample period as well as to various specifications by including/excluding autoregressive and moving average error terms. We found that the estimated coefficients remain more or less fairly robust to different ARIMA specifications and/or sample changes. The sensitivity results have not been reported here but they are available from the authors upon request.

Almost all previous studies indicate that the ANTS equally impacted on inflation in different parts of Australia. In order to test this hypothesis, we have used the Wald test to examine if $\beta_{i l}=0.028(\mathrm{i}=1,2, \ldots, 8)$. It should be noted that, according to Tables 4 and 5, this coefficient for Australia as a whole is 0.028 . According to the Wald test results presented in Table 6, one cannot reject the null hypothesis that $\beta_{l}=0.028$ in all eight capital cities, supporting the view that there was no significant differences in the average price changes among the states and territories arising from the introduction of the GST.

[Table 6 about here]

\section{[Figure 3 about here]}

One may also argue that due to affected pricing behaviour in anticipation of the introduction of the GST, measured inflation may have been impacted prior to the September quarter of 2000. In order to test this possibility we have allowed the GST to impact on inflation for four quarters before its implementation by including a further four separate pulse dummies (each with a non-zero value of 1 in only the 
relevant previous quarter: i.e. September 1999, December 1999, March 2000, June 2000). It is thus hypothesized that the pre-GST effect (if any) on inflation started from the September quarter of 1999. Table 7 presents the Wald test statistics which lend some empirical support to the fact that at least at an aggregate level the GST did not significantly increase inflation prior to its introduction in the eight capital cities including Australia as a whole.

\section{[Table 7 about here]}

\section{Conclusions}

The purpose of this study was to investigate the magnitude and duration of the GST effect on inflation in Australia's eight capital cities as evidenced in available quarterly data from 1948:3 to 2003:1 using the econometric technique of intervention analysis. To our knowledge no one has estimated the impact of the GST in this way. Our analysis provides a further valuable consistency check of others' estimates of the GST inflation impact derived from alternative approaches. It has the great advantage of properly, in statistical sense, allowing for any discernible systematic variation existing in the underlying inflation process, and distilling out from that variation the impact of the GST introduction. Our contribution also lies in determining the extent of regional differences in impact.

We find that the national effect was a one-off lift in inflation - measured quarter-to-quarter - of $2.8 \%$ in the quarter of the introduction of the GST (viz. the September quarter of 2000). There were no statistically significant effects beyond this first quarter. As far as different regions - proxied by the eight State and Territory capital cities - were concerned, the estimates ranged from 2.6\% (Sydney) up to 3.3\% (Hobart). Again there was no statistically significant evidence to suggest any residual impact after the quarter of introduction. 
Finally, though the point estimates for the eight capitals varied from $2.6 \%$ to $3.3 \%$, these differences were not found to be statistically significant from the national point estimate of $2.8 \%$. Thus, it could be concluded that the impact was approximately uniform across the nation and limited to just the quarter of introduction. The actual estimate of $2.8 \%$ is also quite consistent with a number of other earlier estimates obtained from quite different methods.

Table 1 A Summary of the Previous Estimates of the Inflationary Effect of GST/ANTS

\begin{tabular}{lc}
\hline \multicolumn{1}{c}{ Previous Studies } & $\begin{array}{c}\text { Effect on inflation } \\
(\%)\end{array}$ \\
\hline Queensland Treasury (2001) & 2.75 \\
Commonwealth Treasury (2000) & 2.75 \\
ACCC (2001) & $3.70-4.00$ \\
ACCC (2003) & 3.00 \\
Warren et al. (1999) & 2.00 \\
New South Wales Treasury (2001) & $2.50-3$ \\
Present study & 2.80 \\
\hline
\end{tabular}


Figure 1 The Quarterly Inflation Rate in Eight Capital Cities of Australia During 1948:4-2003:1
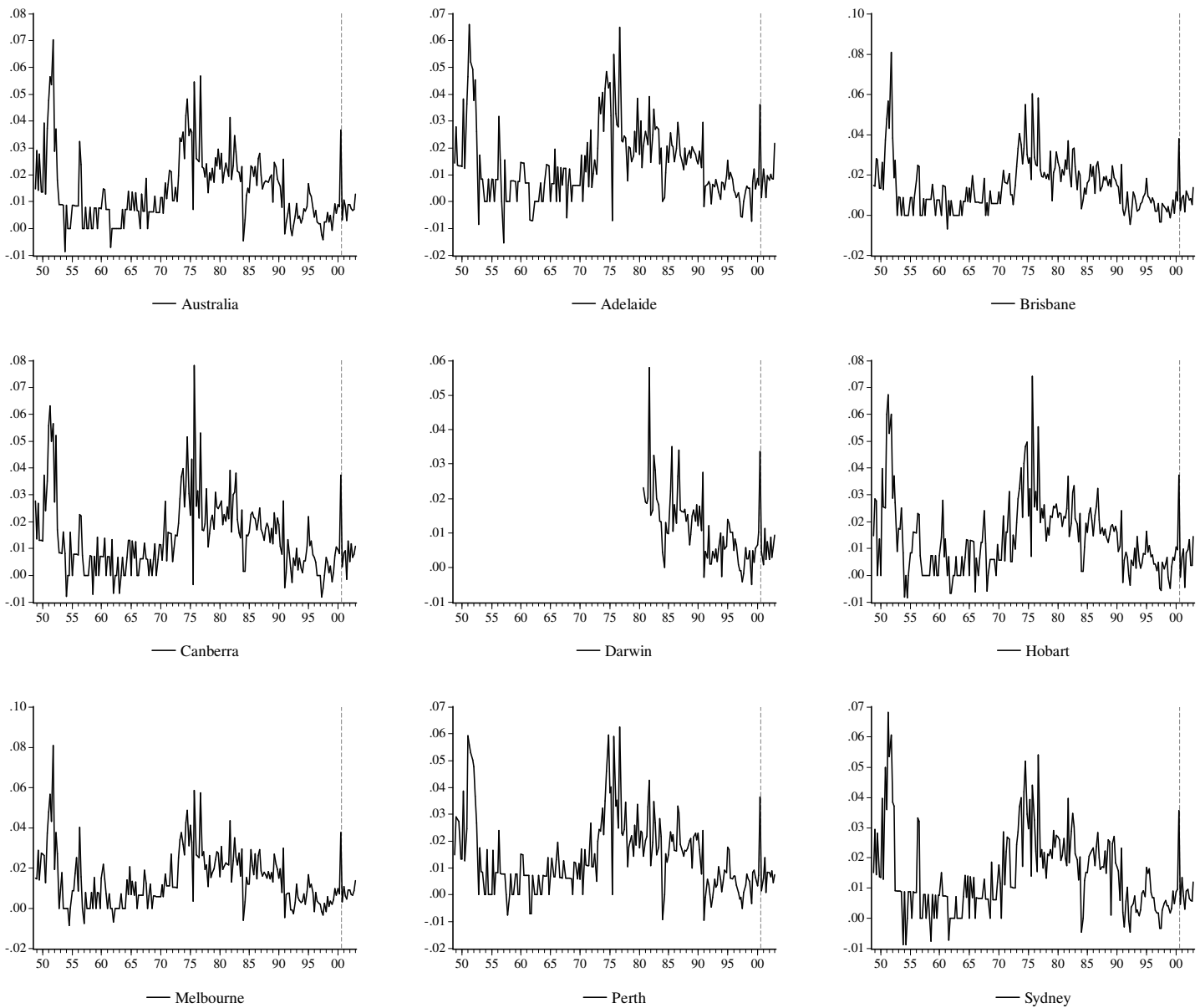

Notes: a) the dotted line coincides with the third quarter of 2000 when the GST was introduced. b) The quarterly inflation rate has been calculated by $\Delta \ln \left(P_{t}\right)$. c) the data on the rate of inflation in Darwin only cover the 1980:4-2003:1 period.

Source: Australian Bureau of Statistics (2003), Consumer Price Index, cat. 6401.0, Table 1B, Canberra. 
Table 2 Summary Statistics of the Data Employed: Quarterly Inflation Rate $\Delta \ln \left(P_{t}\right)$. 1948:4-2003:1

\begin{tabular}{|c|c|c|c|c|}
\hline City & Mean & Maximum & Minimum & Std. Dev. \\
\hline Adelaide & 0.014 & 0.066 & -0.016 & 0.014 \\
\hline Brisbane & 0.014 & 0.081 & -0.007 & 0.013 \\
\hline Canberra & 0.014 & 0.078 & -0.008 & 0.014 \\
\hline Darwin & 0.011 & 0.058 & -0.005 & 0.010 \\
\hline Hobart & 0.014 & 0.074 & -0.008 & 0.014 \\
\hline Melbourne & 0.014 & 0.081 & -0.009 & 0.014 \\
\hline Perth & 0.014 & 0.062 & -0.009 & 0.014 \\
\hline Sydney & 0.014 & 0.068 & -0.009 & 0.013 \\
\hline Australia & 0.014 & 0.070 & -0.009 & 0.013 \\
\hline
\end{tabular}


Table 3 ADF and KPSS Test Results 1948:3-2003:1

\begin{tabular}{lccc}
\hline \multirow{2}{*}{ Variable } & \multicolumn{2}{c}{ ADF test } & \multirow{2}{*}{$\begin{array}{c}\text { KPSS } \\
\text { Statistics }\end{array}$} \\
\cline { 2 - 3 } & $\begin{array}{c}\text { ADF } \\
\text { statistics }\end{array}$ & $\begin{array}{c}\text { Optimum } \\
\text { lag }\end{array}$ & \\
\hline $\ln \left(P_{t}\right):$ & & & \\
Adelaide & -0.63 & 4 & $1.90^{*}$ \\
Brisbane & -0.61 & 4 & $1.91^{*}$ \\
Canberra & -0.74 & 4 & $1.90^{*}$ \\
Darwin & $-4.78^{*}$ & 1 & $1.17^{*}$ \\
Hobart & -0.93 & 4 & $1.91^{*}$ \\
Melbourne & -0.68 & 3 & $1.91^{*}$ \\
Perth & -0.64 & 4 & $1.91^{*}$ \\
Sydney & -0.73 & 3 & $1.91^{*}$ \\
Australia & -0.73 & 3 & $1.91^{*}$ \\
$\Delta l n\left(P_{t}\right):$ & & & \\
Adelaide & & 4 & 0.19 \\
Brisbane & $-3.47^{*}$ & 3 & 0.21 \\
Canberra & $-3.31^{*}$ & 4 & 0.189 \\
Darwin & $-3.18^{*}$ & 3 & $0.909^{*}$ \\
Hobart & -1.34 & 4 & 0.205 \\
Melbourne & $-3.52^{*}$ & 4 & 0.201 \\
Perth & $-3.84^{*}$ & 4 & 0.193 \\
Sydney & $-3.26^{*}$ & 4 & 0.199 \\
Australia & $-3.68^{*}$ & 4.203 \\
\hline Notes: a) P & $-3.68^{*}$ & 4 & 0.203 \\
\hline
\end{tabular}

Notes: a) P denotes the consumer price index. b) "indicates that the corresponding null hypothesis is rejected at the 5\% significance level. c) The data on the rate of inflation in Darwin only cover the 1980:3-2003:1. d) The Akaike Information Criterion has been used as a guide to determine the optimal lag length. 
Table 4 Estimated Coefficients for the Intervention Model, $\Delta \ln \left(P_{i t}\right)$

\begin{tabular}{|c|c|c|c|c|c|c|c|c|c|}
\hline $\begin{array}{c}\text { Estimated } \\
\text { Coefficients }\end{array}$ & Adelaide & Brisbane & Canberra & Darwin & Hobart & Melbourne & Perth & Sydney & Australia \\
\hline$\mu_{0}$ & $\begin{array}{l}0.013 \\
{[0.13]}\end{array}$ & $\begin{array}{c}0.014 \\
{[0.00]}\end{array}$ & $\begin{array}{c}0.014 \\
{[0.00]}\end{array}$ & $\begin{array}{l}0.010 \\
{[0.00]}\end{array}$ & $\begin{array}{c}0.014 \\
{[0.00]}\end{array}$ & $\begin{array}{l}0.014 \\
{[0.00]}\end{array}$ & $\begin{array}{c}0.013 \\
{[0.00]}\end{array}$ & $\begin{array}{l}0.014 \\
{[0.00]}\end{array}$ & $\begin{array}{c}0.014 \\
{[0.00]}\end{array}$ \\
\hline$\beta_{1}$ & $\begin{array}{l}0.028 \\
{[0.00]}\end{array}$ & $\begin{array}{l}0.029 \\
{[0.00]}\end{array}$ & $\begin{array}{l}0.026 \\
{[0.01]}\end{array}$ & $\begin{array}{l}0.026 \\
{[0.00]}\end{array}$ & $\begin{array}{l}0.027 \\
0.01]\end{array}$ & $\begin{array}{l}0.029 \\
{[0.00]}\end{array}$ & $\begin{array}{c}0.029 \\
{[0.00]}\end{array}$ & $\begin{array}{l}0.026 \\
{[0.00]}\end{array}$ & $\begin{array}{c}0.028 \\
{[0.00]}\end{array}$ \\
\hline$\beta_{2}$ & $\begin{array}{l}-0.007 \\
{[0.45]}\end{array}$ & $\begin{array}{l}-0.007 \\
{[0.48]}\end{array}$ & $\begin{array}{l}-0.009 \\
{[0.29]}\end{array}$ & $\begin{array}{l}-0.003 \\
{[0.71]}\end{array}$ & $\begin{array}{c}-0.010 \\
0.27]\end{array}$ & $\begin{array}{l}-0.006 \\
{[0.53]}\end{array}$ & $\begin{array}{c}-0.004 \\
{[0.66]}\end{array}$ & $\begin{array}{l}-0.005 \\
{[0.59]}\end{array}$ & $\begin{array}{l}-0.006 \\
{[0.48]}\end{array}$ \\
\hline$\beta_{3}$ & $\begin{array}{l}0.003 \\
{[0.72]}\end{array}$ & $\begin{array}{l}-0.002 \\
{[0.84]}\end{array}$ & $\begin{array}{l}-0.002 \\
{[0.86]}\end{array}$ & $\begin{array}{l}-0.007 \\
{[0.36]}\end{array}$ & $\begin{array}{l}-0.004 \\
{[0.67]}\end{array}$ & $\begin{array}{l}0.001 \\
{[0.93]}\end{array}$ & $\begin{array}{c}0.000 \\
{[0.99]}\end{array}$ & $\begin{array}{c}0.004 \\
{[0.67]}\end{array}$ & $\begin{array}{c}0.002 \\
{[0.86]}\end{array}$ \\
\hline$\beta_{4}$ & $\begin{array}{l}-0.001 \\
{[0.94]}\end{array}$ & $\begin{array}{l}0.000 \\
{[0.99]}\end{array}$ & $\begin{array}{l}-0.002 \\
{[0.83]}\end{array}$ & $\begin{array}{l}0.005 \\
{[0.56]}\end{array}$ & $\begin{array}{r}-0.001 \\
{[0.88]}\end{array}$ & $\begin{array}{l}-0.003 \\
{[0.77]}\end{array}$ & $\begin{array}{c}0.005 \\
{[0.60]}\end{array}$ & $\begin{array}{l}-0.002 \\
{[0.82]}\end{array}$ & $\begin{array}{l}-0.001 \\
{[0.92]}\end{array}$ \\
\hline$\beta_{5}$ & $\begin{array}{l}-0.008 \\
{[0.40]}\end{array}$ & $\begin{array}{l}-0.009 \\
{[0.32]}\end{array}$ & $\begin{array}{l}-0.011 \\
{[0.25]}\end{array}$ & $\begin{array}{l}-0.005 \\
{[0.53]}\end{array}$ & $\begin{array}{l}-0.013 \\
{[0.16]}\end{array}$ & $\begin{array}{l}-0.005 \\
{[0.55]}\end{array}$ & $\begin{array}{l}-0.009 \\
{[0.30]}\end{array}$ & $\begin{array}{c}-0.006 \\
{[0.49]}\end{array}$ & $\begin{array}{l}-0.006 \\
{[0.48]}\end{array}$ \\
\hline$\rho_{l}$ & $\begin{array}{l}0.105 \\
{[0.50]}\end{array}$ & $\begin{array}{l}0.862 \\
{[0.00]}\end{array}$ & $\begin{array}{l}0.794 \\
{[0.00]}\end{array}$ & $\begin{array}{l}0.278 \\
{[0.01]}\end{array}$ & $\begin{array}{c}0.421 \\
{[0.00]}\end{array}$ & $\begin{array}{l}-0.338 \\
{[0.00]}\end{array}$ & - & $\begin{array}{c}0.873 \\
{[0.00]}\end{array}$ & $\begin{array}{c}0.879 \\
{[0.00]}\end{array}$ \\
\hline$\rho_{2}$ & - & - & - & $\begin{array}{c}0.201 \\
{[0.08]}\end{array}$ & $\begin{array}{c}0.277 \\
{[0.00]}\end{array}$ & $\begin{array}{c}0.543 \\
{[0.00]}\end{array}$ & - & - & - \\
\hline$\rho_{3}$ & - & - & - & $\begin{array}{l}0.252 \\
{[0.02]}\end{array}$ & - & - & - & - & - \\
\hline$\rho_{4}$ & - & - & - & - & - & - & $\begin{array}{c}0.643 \\
{[0.00]}\end{array}$ & - & - \\
\hline$\phi(r=3)$ & - & - & - & - & - & $\begin{array}{c}0.468 \\
{[0.00]}\end{array}$ & - & - & - \\
\hline$\phi(r=4)$ & $\begin{array}{c}0.863 \\
{[0.00]}\end{array}$ & $\begin{array}{c}0.139 \\
{[0.07]}\end{array}$ & $\begin{array}{c}0.259 \\
{[0.00]}\end{array}$ & - & $\begin{array}{c}0.248 \\
{[0.00]}\end{array}$ & & - & - & - \\
\hline$\theta_{1}$ & $\begin{array}{c}0.280 \\
{[0.04]}\end{array}$ & $\begin{array}{l}-0.416 \\
{[0.00]}\end{array}$ & $\begin{array}{l}-0.587 \\
{[0.00]}\end{array}$ & - & - & $\begin{array}{l}0.683 \\
{[0.00]}\end{array}$ & $\begin{array}{c}0.422 \\
{[0.00]}\end{array}$ & $\begin{array}{c}-0.543 \\
{[0.00]}\end{array}$ & $\begin{array}{l}-0.567 \\
{[0.00]}\end{array}$ \\
\hline$\theta_{2}$ & $\begin{array}{l}0.459 \\
{[0.00]}\end{array}$ & - & $\begin{array}{l}0.303 \\
{[0.00]}\end{array}$ & - & - & - & $\begin{array}{c}0.467 \\
{[0.00]}\end{array}$ & $\begin{array}{c}0.195 \\
{[0.01]}\end{array}$ & $\begin{array}{c}0.248 \\
{[0.00]}\end{array}$ \\
\hline$\theta_{3}$ & $\begin{array}{c}0.413 \\
{[0.00]}\end{array}$ & - & - & - & - & - & $\begin{array}{c}0.486 \\
{[0.00]}\end{array}$ & - & - \\
\hline$\theta_{4}$ & $\begin{array}{l}-0.497 \\
{[0.00]}\end{array}$ & - & - & - & - & - & - & - & - \\
\hline $\bar{R}^{2}$ & 0.529 & 0.499 & 0.515 & 0.351 & 0.510 & 0.509 & 0.562 & 0.512 & 0.557 \\
\hline DW & 1.98 & 2.03 & 1.97 & 2.10 & 1.91 & 2.02 & 2.06 & 1.96 & 1.92 \\
\hline AIC & -6.43 & -6.52 & -6.42 & -6.67 & -6.39 & -6.42 & -6.53 & -6.49 & -6.64 \\
\hline $\mathrm{SC}$ & -6.24 & -6.38 & -6.26 & -6.41 & -6.25 & -6.26 & -6.38 & -6.35 & -6.50 \\
\hline $\begin{array}{l}Q \text {-statistic } \\
\text { (24 lags) }\end{array}$ & $\begin{array}{c}25.0 \\
{[0.12]}\end{array}$ & $\begin{array}{c}13.0 \\
{[0.91]}\end{array}$ & $\begin{array}{c}13.5 \\
{[0.85]}\end{array}$ & $\begin{array}{c}27.4 \\
{[0.16]}\end{array}$ & $\begin{array}{c}25.8 \\
{[0.21]}\end{array}$ & $\begin{array}{c}20.4 \\
{[0.43]}\end{array}$ & $\begin{array}{c}26.1 \\
{[0.16]}\end{array}$ & $\begin{array}{c}21.1 \\
{[0.45]}\end{array}$ & $\begin{array}{c}26.2 \\
{[0.20]}\end{array}$ \\
\hline $\begin{array}{l}L M \\
\text { (4 lags) }\end{array}$ & $\begin{array}{c}0.17 \\
{[0.95]}\end{array}$ & $\begin{array}{c}0.50 \\
{[0.74]}\end{array}$ & $\begin{array}{c}0.56 \\
{[0.69]}\end{array}$ & $\begin{array}{c}0.94 \\
{[0.44]}\end{array}$ & $\begin{array}{c}2.0 \\
{[0.10]}\end{array}$ & $\begin{array}{c}0.58 \\
{[0.68]}\end{array}$ & $\begin{array}{c}0.84 \\
{[0.50]}\end{array}$ & $\begin{array}{c}0.70 \\
{[0.59]}\end{array}$ & $\begin{array}{c}1.44 \\
{[0.22]}\end{array}$ \\
\hline
\end{tabular}

Note: The figures in square brackets are the corresponding p-values. 
Figure 2 Correlograms of Residuals for the Estimated Intervention Models (continued)

\begin{tabular}{|c|c|c|c|c|c|}
\hline \multicolumn{2}{|c|}{ Adelaide } & \multicolumn{2}{|c|}{ Brisbane } & \multicolumn{2}{|c|}{ Canberra } \\
\hline Autocorrelation & Partial Correlation & Autocorrelation & Partial Correlation & Autocorrelation & Partial Correlation \\
\hline \begin{tabular}{l|l}
1 & 1
\end{tabular} & $1 \mid 1$ & 111 & 111 & $1 \mid 1$ & 1|1 \\
\hline $1: 1$ & $1: 1$ & 11 & 111 & 11 & 11 \\
\hline \begin{tabular}{l|l}
1 & 1
\end{tabular} & \begin{tabular}{l|l}
1 & 1
\end{tabular} & $1 / 1$ & 1 & 1/1 & 1/1 \\
\hline \begin{tabular}{l|l}
1 & 1
\end{tabular} & \begin{tabular}{l|l}
1 & 1
\end{tabular} & $1 / 1$ & 101 & \begin{tabular}{l|l}
1 & 1
\end{tabular} & 101 \\
\hline 1 & 1 & 11 & 11 & 111 & 11 \\
\hline 11 & 111 & 111 & 111 & 11 & 1,1 \\
\hline . & . & e & e & 1 & 1 \\
\hline - 1 & - 1 & 111 & 111 & 11 & 11 \\
\hline \begin{tabular}{l|l}
1 & 1
\end{tabular} & \begin{tabular}{l|l}
1 & 1
\end{tabular} & 111 & 111 & 1 & 1 \\
\hline 11 & 11 & 111 & 111 & 111 & 1ן 1 \\
\hline $1 / 1$ & $1 / 1$ & 111 & 11 & 111 & 11 \\
\hline 1 & 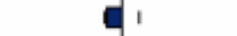 & 1 & 1 & إ| 1 & I) \\
\hline $1 / 1$ & $1 / 1$ & 111 & 111 & $1 / 1$ & $1 / 1$ \\
\hline 11 & 111 & 111 & $1 \mid 1$ & 11 & 11 \\
\hline 1 & 1 & 14 & 11 & 1 & 1 \\
\hline 111 & 111 & 11 & 1 & 11 & 11 \\
\hline 1 & 111 & 111 & 1 & 1|1 & ו1 \\
\hline 111 & 111 & 1 & $\begin{array}{lll}1 & 1\end{array}$ & | || & ון 1 \\
\hline 1 & 1 & $1 / 1$ & $1 / 1$ & 111 & 111 \\
\hline 1 & 10 & 17 & 10 & 1 & 16 \\
\hline 11 & 11 & 11 & 111 & 11 & 1 \\
\hline 1|| & 101 & 111 & 14 & $1 \mid$ & 111 \\
\hline 11 & 11 & \begin{tabular}{l|l}
1 & 1
\end{tabular} & \begin{tabular}{l|l}
1 & 1
\end{tabular} & 111 & 11 \\
\hline 111 & 111 & 111 & 11 & 11 & 11 \\
\hline
\end{tabular}

\begin{tabular}{|c|c|c|c|c|c|}
\hline \multicolumn{2}{|c|}{ Darwin } & \multicolumn{2}{|c|}{ Hobart } & \multicolumn{2}{|c|}{ Melbourne } \\
\hline Autocorrelation & Partial Correlation & Autocorrelation & Partial Correlation & Autocorrelation & Partial Correlation \\
\hline 11 & 111 & 111 & 111 & 111 & 111 \\
\hline 11 & 111 & 11 & 11. & $1] 1$ & $1] 1$ \\
\hline 11 & 11 & 11 & 11 & \begin{tabular}{l|l}
1 & 1
\end{tabular} & \begin{tabular}{l|l}
1 & 1
\end{tabular} \\
\hline 1 & 1 & $1 \sqrt{1}$ & $1 \sqrt{1}$ & 111 & 111 \\
\hline $1 \Gamma 1$ & $1 \Gamma 1$ & 111 & 111 & 1 & $1 / 1$ \\
\hline 11 & \begin{tabular}{l|l}
1 & 1
\end{tabular} & 111 & $1\} 1$ & 11 & $1 \sqrt{1}$ \\
\hline 1 & 11 & 1 & 1 & 111 & 111 \\
\hline 11 & 111 & 17 & 10 & 111 & 111 \\
\hline 11 & 1 & $1[1$ & $1[1$ & 11 & 111 \\
\hline 11 & 1 & \begin{tabular}{l|l}
1 & 1
\end{tabular} & \begin{tabular}{l|l}
1 & 1
\end{tabular} & 111 & 111 \\
\hline 11 & 11 & 1 & 111 & 11 & $1 / 1$ \\
\hline 11 & 11 & 111 & 111 & 1 & 11 \\
\hline 1 & 1 & 1 & $1]$ & 11 & 11 \\
\hline 11 & 1 & 141 & 11 & 11 & 11 \\
\hline ' & $1 \boldsymbol{\theta}$ & 11 & 111 & 1 ' & 11 \\
\hline 11 & & 17 & 1. & 10 & 12 \\
\hline 11 & 1 & $1 / 1$ & 1 & $1 \sqrt{11}$ & 11 \\
\hline 1 1 & 1 & 1 & 1 & 11 & 11 \\
\hline 1 & $\begin{array}{lll}1 & 1\end{array}$ & 11 & 111 & 11 & 11 \\
\hline ' & e & 10 & 1 & 10 & 10 \\
\hline 11 & 1 & $1 \sqrt{1}$ & $1 \longdiv { 1 }$ & 111 & 11 \\
\hline 11 & 111 & 11 & 11 & 11 & 11 \\
\hline 11 & 11 & 1 & 1 & 11 & 11 \\
\hline 111 & $1 \mid 1$ & 10 & 10 & 111 & 111 \\
\hline
\end{tabular}


Figure 2 Correlograms of Residuals for the Estimated Intervention Models

\begin{tabular}{|c|c|c|c|c|c|}
\hline \multicolumn{2}{|c|}{ Perth } & \multicolumn{2}{|c|}{ Sydney } & \multicolumn{2}{|c|}{ Australia } \\
\hline Autocorrelation & Partial Correlation & Autocorrelation & Partial Correlation & Autocorrelation & Partial Correlation \\
\hline 11 & 111 & 111 & 111 & 111 & 111 \\
\hline 11 & 11 & iाi & 111 & 1) & iा \\
\hline 111 & 11 & 111 & 111 & $1 / 1$ & 11 \\
\hline id & 1. & 1 & 1 & 1 & 1 \\
\hline 111 & 1.1 & 1 & 1 & $\sqrt{1}$ & $\boldsymbol{r}_{1}$ \\
\hline 11 & 11 & 1 & 11 & 1) & 11 \\
\hline in & 1 & 1 & 1 & 1 & ह \\
\hline 11 & 111 & 1. 1 & 1. 1 & 11. & 171 \\
\hline 11 & 11 & 1]1 & $1] 1$ & 111 & 11 \\
\hline $\mathbf{a}_{1}$ & . & 111 & 111 & 11 & 111 \\
\hline 11 & 17 & 111 & 111 & 11 & $1] 1$ \\
\hline $1 \sqrt{1}$ & 11 & 11 & 11 & 11 & 111 \\
\hline 13 & 1] & 11 & 11 & 1 & 1 1) \\
\hline 1 & 1 & 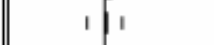 & 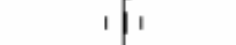 & $1 \sqrt{1}$ & 1 \\
\hline 1 & 11 & 11 & 11 & , & 1 \\
\hline 111 & 1 & 1] 1 & 1 1 & $1]$ & $1]$ \\
\hline $1 \sqrt{1}$ & $1 \sqrt{1}$ & 111 & 111 & 11 & 111 \\
\hline 111 & 1) & 11 & 1 & 11 & 1 \\
\hline 11 & 11 & 11 & 111 & 11 & $1 /$ \\
\hline ש & שי & 1 & 16 & 16 & ב \\
\hline $1 \sqrt{1}$ & $\sqrt{1}$ & $\sqrt{1}$ & 11 & $1 \sqrt{1}$ & $1 \sqrt{1}$ \\
\hline $1 / 1$ & 1.1 & 1 1 & 1]1 & 111 & 11 \\
\hline 111 & 1 & 111 & 1 & 111 & 111 \\
\hline 11 & in & 16 & 1 & $i_{1}$ & $1 b_{1}$ \\
\hline
\end{tabular}


Table 5 The Estimated Effects of

GST on Inflation $\left(\beta_{i 1}\right)$ in 2000:3

\begin{tabular}{lcc}
\hline \multicolumn{1}{c}{ City } & $\beta_{j}=0$ & $\beta_{j} \neq 0$ \\
& \multicolumn{2}{c}{$j=2,3,4,5$} \\
\hline Adelaide & 0.029 & 0.028 \\
Brisbane & 0.032 & 0.029 \\
Canberra & 0.029 & 0.026 \\
Darwin & 0.027 & 0.026 \\
Hobart & 0.033 & 0.027 \\
Melbourne & 0.031 & 0.029 \\
Perth & 0.031 & 0.029 \\
Sydney & 0.026 & 0.026 \\
Australia & 0.028 & 0.028 \\
\hline Note: All the estimated coefficients are \\
statistically significant at 1 per cent level.
\end{tabular}

Table 6 Testing the Equality of the Short-Run Effect of GST on Inflation $\left(\beta_{i I}=0.028\right)$ across Eight Capital Cities

\begin{tabular}{lcc}
\hline \multicolumn{1}{c}{ City } & F statistic & P-value \\
\hline Adelaide & $\mathrm{F}(1,205)=0.004$ & 0.950 \\
Brisbane & $\mathrm{F}(1,208)=0.280$ & 0.597 \\
Canberra & $\mathrm{F}(1,207)=0.015$ & 0.904 \\
Darwin & $\mathrm{F}(1,82)=0.036$ & 0.849 \\
Hobart & $\mathrm{F}(1,207)=0.358$ & 0.551 \\
Melbourne & $\mathrm{F}(1,207)=0.100$ & 0.755 \\
Perth & $\mathrm{F}(1,208)=0.172$ & 0.679 \\
Sydney & $\mathrm{F}(1,212)=0.039$ & 0.844 \\
\hline
\end{tabular}


Figure 3 The Effect of GST on Inflation in the September Quarter of 2000

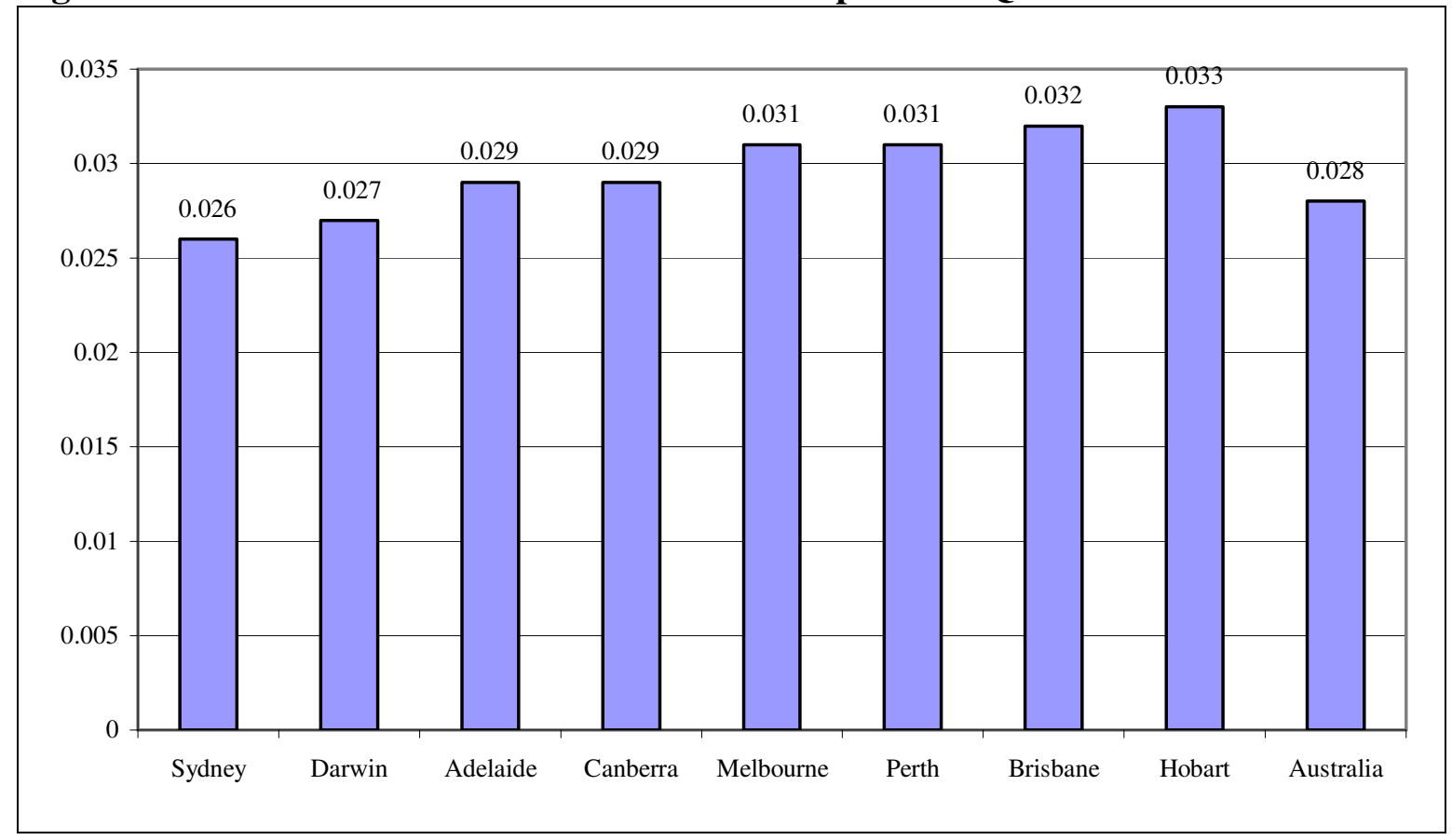

Source: Authors' calculations extracted from the first column of Table 5.

Table 7 Testing the Effect of GST on Inflation Starting From Four Quarters Before Its Introduction (1999:3-2000:2)

\begin{tabular}{lcc}
\hline City & $\begin{array}{c}\mathrm{F} \text {-statistic } \\
\text { Ho: } \beta_{j}=0 \\
\text { where } \mathrm{j}=-1,-2,-3,-4\end{array}$ & P-value \\
\hline Adelaide & $\mathrm{F}(4,197)=0.218$ & 0.928 \\
Brisbane & $\mathrm{F}(4,200)=0.309$ & 0.872 \\
Canberra & $\mathrm{F}(4,199)=0.296$ & 0.880 \\
Darwin & $\mathrm{F}(4,74)=0.150$ & 0.962 \\
Hobart & $\mathrm{F}(4,199)=0.085$ & 0.987 \\
Melbourne & $\mathrm{F}(4,199)=0.173$ & 0.952 \\
Perth & $\mathrm{F}(4,200)=0.169$ & 0.954 \\
Sydney & $\mathrm{F}(4,204)=0.080$ & 0.989 \\
Australia & $\mathrm{F}(4,204)=0.104$ & 0.981 \\
\hline
\end{tabular}

Note: In the estimated ARIMA models there are 9 pulse dummy variables which capture the pre- and post GST effect on inflation in 9 quarters separately starting from 1999:3 to 2001:3. We have allowed the GST to impact on inflation for four quarters prior to its introduction by including four pulse dummies (each with a non-zero value of 1 in only the relevant previous quarter: i.e. September 1999, December 1999, March 2000, June 2000). The above Wald test statistics clearly indicate that inflation did not increase significantly from its underlying systematic pattern prior to the introduction of GST. 


\section{References}

Australian Bureau of Statistics 2003, Consumer Price Index, cat. 6401.0, ABS, Canberra.

Australian Competition and Consumer Commission 2001, Report to the Minister Under Section 75AZ of the Trade Practices Act 1974, Australian Competition and Consumer Commission, Canberra.

Australian Competition and Consumer Commission 2003, GST Final Report: ACCC Oversight of Pricing Responses to the Introduction of the New Tax System, Australian Competition and Consumer Commission, Canberra.

Bausell, C.W. et al. 2001, 'Lifting the Alaskan oil export ban: an intervention analysis', Energy Journal, vol. 22, pp. 81-94.

Bhattacharyya, M.N., and Layton, A.P. 1979, 'Effectiveness of seat belt legislation on the Queensland road toll: an Australian case study in intervention analysis', Journal of the American Statistical Association, vol. 74, pp. 596-603.

Box, G.E.P. and Tiao, G.C. 1975, 'Intervention analysis with applications to economic and environmental problems', Journal of American Statistical Association, vol. 70, pp.70-9.

Box, G.E.P., Jenkins, G.M. and Reinsel, G.C. 1994, Time Series Analysis Forecasting and Control, Prentice-Hall, Upper Saddle River, New Jersey.

Commonwealth Treasury, 2000, Budget Speech 2000-01, Delivered on 9 May 2000 on the Second Reading of the Appropriation Bill (no.1) 2000-01 by the Honourable Peter Costello, The Commonwealth of Australia, Canberra.

Dawkins, P. Johnson, D., 1998, 'The interaction of tax and social security: introduction and overview', Australian Economic Review, vol. 31, pp. 258-62.

Enders, W. Sandler, T., and Cauley, J. 1990, 'Assessing the impact of terroristthwarting policies: an intervention time series approach', Defence Economics, vol. 2, pp. 1-18.

Enders, W., Todd, S. and Parise, G.F. 1992, 'An econometric analysis of the impact of terrorism on tourism', Kyklos, vol. 45, pp. 531-54.

Eviews, 2002, EViews 4 User's Guide, Quantitative Micro Software, Irvine, Ca.

Harvey, A.C. and Durbin, J. 1986, 'The effects of seat belts legislation on British road casualties: a case study in structural time series modelling', Journal of the Royal Statistical Society, Series A. vol. 149, pp. 187-227.

Hogan, T. D. 1984, 'An intervention analysis of the effects of legalized abortion upon U.S. Fertility’, Population Research and Policy Review, vol.3, pp. 201-218. 
Johnson, D.T, Freebairn, J. and Scutella, R. 1999, Evaluation of the Government's Tax Package, Melbourne Institute of Applied Economic and Social Research, University of Melbourne, Melbourne.

Kwiatkowski, D., Phillips, P.C.B., Schmidt, P. and Shin, Y. 1992, 'Testing the null hypothesis of stationarity against the alternative of a unit root: how sure are we that economic time series have a unit root?', Journal of Econometrics, vol. 54, pp. 159-78.

Layton, A. P. 1983, 'The impact of increased penalties on Australian drink/driving behaviour', Logistics and Transportation Review, vol. 19, pp. 261 -66.

Layton, A.P. and Weigh, J.C. 1983, 'The efficacy of some recent Australian road safety policy initiatives', Logistics and Transportation Review, vol. 19, pp. 267 -78.

Ljung, G. and Box, G. 1979, 'On a measure of lack of fit in time series models', Biometrika, vol. 66, pp. 265-270.

Lloyd, T, Morrissey, O. and Reed, G.(1998), Estimating the impact of anti-dumping and anti-cartel actions using intervention analysis, Economic Journal, vol.108, pp. 458-76.

New South Wales Treasury, 2001, 2000-01 Half Yearly Budget Review, NSW Treasury, Sydney.

Queensland Treasury, 2001, CPI Exclusive of GST Effects: June Quarter 2001 (a briefing note), Office of Economic and Statistical Research, Queensland Treasury, Brisbane.

Sharma, P. and Khare, M. 1999, 'Application of intervention analysis for assessing the effectiveness of CO pollution control legislation in India', Transportation Research: Part D: Transport and Environment, vol. 4, pp. 427-32.

Thompson, P.A. and Noordewier, T. 1992, 'Estimating the effects of consumer incentive programs on domestic automobile sales', Journal of Business \& Economic Statistics, vol. 10, pp. 409-17.

Warren, N. et al., 1999, Distributional Impact of Possible Tax Reform Packages, Report to Senate Select Committee on a New Tax System, National Centre for Social and Economic Modelling (NATSEM), University of Canberra, Canberra. 